\title{
Watching the Kiwis: \\ New Zealanders' Rules of Social Interaction - an Introduction'
}

\author{
BRIGITTE BÖNISCH-BREDNICH
}

To begin with I should make it clear that, I do actually like New Zealand and I quite enjoy living here! First of all, I would like to thank the Stout Research Centre for New Zealand Studies for hosting and helping me plan the 'Watching the Kiwis' seminar series. Secondly, I may have to explain how this series came about. Although it was finally prompted into action by our reading of Kate Fox's book Watching the English, Lydia Wevers, Richard Hill and myself had had this project in mind for quite some time. ${ }^{2}$ There are many anthropologists and other social scientists working and teaching in New Zealand, but not so very many who actually do research on New Zealand topics or, even more specifically, on things as ordinary as shopping, moving, holidaying, gardening, drinking and watching television, let alone reflecting on stereotypical Kiwi behaviour. Although the topics discussed over the two-and-a-half month seminar series and then included in this journal are really just looking at some loosely connected pieces of a complicated puzzle, it is - at least - the start of a closer examination of the everyday lives of New Zealand people.

The 'Watching the Kiwis' series consisted of eight papers presented on quite extensive projects of single academics working on New Zealand topics. The seminar series also included two panels, in which I asked social scientists (mainly anthropologists who work in New Zealand, although not necessarily on New Zealand topics) to share their impressions of this small country, its society, its people and also its social structures and patterns.

The first panel comprised of Chris Shore, Professor of Anthropology at the University of Auckland; David Pearson, Reader in Sociology at Victoria University of Wellington; Theresa Sawicka, who holds a PhD in Anthropology and heads the Research Office at Victoria University of Wellington; and James Urry, Reader in Anthropology at Victoria University of Wellington. Each of them is British (most actually English) and came to New Zealand at some point during the last 30 years. The leading question and the obvious task for this panel was to compare countries and to reflect upon how English, or non-English, New Zealanders are. 
The second panel was made up of anthropologists who have either lived in a number of different countries before coming here, or are actually Kiwis who lived overseas for a long time and have had to readjust from life in Europe, America or India to a relatively small-scale society. They are $\mathrm{Dr}$ Teresia Teaiwa, Senior Lecturer in Pacific Studies at Victoria University of Wellington; Dr Charles Sedgwick, of Victoria University of Wellington, who holds degrees in both Anthropology and Sociology; and Dr Anke Linkenbach-Fuchs, an anthropologist from Canterbury University.

Here, however, I will briefly outline some of the ideas I believe need to be discussed first. ${ }^{4}$ After some introductory comments about the nation-state, globalisation and other unavoidable topics, I will provide a little insight into Watching the English: The hidden rules of English behaviour by Kate Fox, and discuss my amazement at how many things I learned about New Zealand while reading up on the English. I will also discuss some of Fox's main topics, compare them with my observations on New Zealand and share some of my ideas on how you New Zealanders are, how you appear to be and what sense it might make to think in certain ways about something approaching national characteristics.

\section{Are we allowed to discuss the topic of a national character?}

Books on national character are all the rage in Europe and have been for about the last ten years. ${ }^{5}$ Every European country, or at least the bigger ones, seems to want to know who they are or what remains of them when one deducts the influence of the European Union, the United States, McDonalds, Coca-Cola, Microsoft and regional rather than national idiosyncrasies. There is a definite urge to find something to call truly French, English or German, which really distinguishes one state and its people from another.

Every book written for this purpose gives very specific reasons for the need for self-branding. ${ }^{6}$ England, for example, needed to re-examine itself following the collapse of the Empire after years of being the unquestioned cultural and political power that defined others but not itself; Germany had to find a new way of looking at itself, working through and accepting the trauma of guilt, disaster and the horrific consequences of the Nazi period; Austria has just begun a similar process and is starting to wonder what it might and will become. New Zealand's wish to define itself or be described by others is often explained by its being so distant on the map, being so small, thinly populated and insignificant in world politics. But does this really explain its desperate wish to hear words of praise? The most beautiful country in the world, so friendly and green and nuclear-free, nearly the best at everything, at least in the southern hemisphere, and surely better than Australia. 
According to recent theorists (anthropologists and sociologists alike), globalisation is also a driving factor for national insecurity and the need to reassure ourselves as to where we are and what we are as nations. 'The principal effect of globalization, as far as I can tell, has been an increase in nationalism and tribalism, a proliferation of struggles for independence, devolution and self-determination and a resurgence of concern about ethnicity and cultural identity,' at least in the majority of the so-called western world?

What I cannot really address here are the complicating factors of a real in-depth analysis of a state, such as multiculturalism, ethnicity or social change over time. My discussion, I am afraid, will be all about mainstream behaviour, and therefore the general rules of the majority. But rules and patterns are not there to address anything that goes, but rather to explain the mainstream of things, how a society works and runs, and therefore the set of rules to which people are expected to adhere. To a very high degree, such rules are set by the most powerful cultural group, in New Zealand's case, Pākehā. Some of these rules are in tune with or are adapted from Māori culture, but many still echo British voices from the former motherland.

\section{Comparing countries: Watching the English - Watching the Kiwis}

Kate Fox's book is based on 12 years of well-funded research (and there are still some important aspects missing in it), whereas this paper is based on fleeting observations, recollections and impressions of Kiwis formed while observing my friends or strangers on Lambton Quay and during the odd holiday in various parts of New Zealand. It is still quite unstructured, random and influenced by my German background. This paper, which I hope to extend by conducting much more in-depth research, is also, in its style of delivery, very much influenced not just by what I have observed but also the nature of what I have read so far. It is light in tone because I have dived not just into the very funny and witty Kate Fox but also into books like The Xenophobe's Guide to the Kiwis, The Half-Gallon Quarter-Acre Pavlova Paradise, Pavlova Paradise Revisited, The Passionless People and various other rather more dubious sources including the Dominion Post and the Sunday Star-Times. ${ }^{8}$ I have, needless to say, also looked at statistics, linguistic studies on small talk, more official New Zealand histories and Peter Howland's extremely humorous Lotto, Long-Drops \& Lolly Scrambles: The Extra-Ordinary Anthropology of Middle New Zealand. ${ }^{9}$

Kate Fox starts her book with the words:

My aim, if you like, was to provide a 'grammar' of English behaviour. Native speakers can rarely explain the grammatical rules of their 
own language. In the same way, those who are most 'fluent' in the rituals, customs and traditions of a particular culture generally lack the detachment necessary to explain the 'grammar' of these practices in an intelligible manner. This is why we have anthropologists. ${ }^{10}$

We conducted research on celebration, cyber-dating, summer holidays, embarrassment, corporate hospitality, van drivers, risk taking, . . . , sex, mobile-phone gossip and the relationship between tea-drinking and DIY (this last dealing with burning social issues such as 'how many cups of tea does it take the average Englishman to put up a shelf?')."

One of the fun parts of this book is that Fox gives as cornerstones for all topics covered the appropriate English vocabulary. Stereotypes of Englishness she considers as central for her own and other people's research are:

'reserve', 'politeness', 'weather-talk', 'hooliganism', 'hypocrisy', 'privacy', 'anti-intellectualism', 'queuing', 'compromise', 'fair play', 'humour', 'classconsciousness', 'eccentricity' . . . they all had complex layers of rules and codes which are not visible to the untrained eye. ${ }^{12}$

The central hypothesis of Kate Fox's book is that the core of all English behaviour lies in 'social dis-ease' but also in class consciousness. Class pervades all aspects of English life and culture, and therefore permeates all the areas covered in this book.13 'Every English person (whether we admit it or not) is aware of and highly sensitive to all of the delicate divisions and calibrations involved in such [class] judgements'. ${ }^{14}$

This is not quite the way it works in New Zealand, although we also have carefully established ways of opening and conducting conversations, especially small talk. However, Kiwis seem to be more at ease than at disease with each other, and often really seem to enjoy meeting new people. This indicates the reasons for treating social situations cautiously are different from the English ones, although the rules around such social interactions seem to be rather similar.

I suggest, therefore, that the core of most New Zealand behaviour lies in characteristics handed down from the English and carried on by the deeply embedded belief in and wish for egalitarianism: everybody should be the same and if they are not they should, at the very least, pretend to be. This is closely interlinked with the fact that New Zealand still is, at its core, very much a face-to-face society: it is more than just likely that two people will meet again, that people one knows are connected to the person to whom one is talking; and, therefore, it is of far greater importance to treat things lightly rather than being 'true to one's heart' and, by acting this out, endangering social networks in future.

So there are very good reasons for this carefully developed Kiwi system of playing down differences, denying hierarchies or at least acting them out in a 
more backstage kind of way, applying various tactics of disguising difference and constantly creating a social plateau. All this makes working in New Zealand very puzzling for a newcomer, because you learn very quickly that all this is actually not true or, at least, it is only true on the surface. One soon realises that there are, as in every society, boundaries, social classes, status systems and signs and indicators for them; they are just harder to detect because these rules are written in a code. For foreigners they often may as well be written in invisible ink. However, while Fox and others writing about England suggest the English are constantly acting out these differences, unconsciously and consciously reflecting on them and reassuring themselves of their validity, in New Zealand a whole set of crucial social rules and energies are caught up in doing exactly the opposite: pretending boundaries and hierarchies do not exist; that while differences are possible, they do not really matter or come into play; that what is important is that everybody is really the same, everybody gets a fair go.

The question here for the anthropologist is why this kind of delusional behaviour (we do not want to call it hypocrisy) makes sense. Why is this deeply embedded need for social plateauing essential for the overall Kiwi well-being?

To answer this requires a little excursion into history (something that is sadly missing in Kate Fox's book). This has to do with what James Belich calls the 'Pākehā Treaty', the conditions and promises of settlement in the nineteenth century. ${ }^{15}$ The deal for coming to New Zealand was that people would not have to put up with the 'paraphernalia' of the English class system. That did not mean that class would be absent in New Zealand, but the promise was that it would not pervade every single aspect of everyday life. All people, regardless of their background, would have similar clothing, housing and food, and while employer-employee relationships still existed, bosses would have to treat you as an equal outside of the working relationship.

This contract of 'sameness' was and is a wonderful thing, but it has, over time, mutated into a somewhat delusional egalitarianism, into an inability and unwillingness to acknowledge difference, talent, expertise and excellence. It has become something that New Zealanders still carry as a promise and a burden without realising it, and on which they are quite unable to reflect. It is just part of the national character. Small poppies have to be encouraged to think more highly of themselves than they really are, while tall ones are put down, moaned about and taught to crouch and bend.

There are growing exceptions to this rule. One is the area of sport: sportsmen and women, whose abilities are apparently more genetic than, for example, academic talents, are allowed to stand out. Excellence in sport is something to be admired, to represent the country to the outside 
world. Sportsmen and women are praised, admired and socially elevated in times of success, although they are not encouraged to boast about their achievements themselves (yet another rule). Sir Edmund Hillary's famous quote about 'knocking the bastard off' sums up rules around articulating, or rather downplaying, success, of being humble because one can be, but also because humbleness blends one back into New Zealand society while at the same time giving room and allowance for standing taller, at least for a while. Vocabulary for achievement, if there is a need to talk about it at all, is consequently the opposite of self-praise: 'that wasn't bad', 'I've done worse before', 'that was pretty much okay', or even 'I quite enjoyed this one'.

One of the central hypotheses in Kate Fox's book is that at the core of nearly all English behaviour is a deeply embedded 'social dis-ease'. Weather talk is not about the weather, it is actually about enabling the English to be polite, to find a way to communicate with each other and creating a chance for agreement and rapport. Agreeing on the weather is therefore much more important than actually being honest about one's opinion of the weather. ${ }^{16}$ This also applies to countless other situations in English life: agreeing on how lovely your female companion looks in an impossible outfit, how great a truly boring party is, how awful the wind is and so on. Fox calls this 'grooming talk', and the rules for it are much the same here in New Zealand. ${ }^{17}$ However, Bill Bryson says in his book about the English that there is hardly any interesting weather to speak of, whereas it is definitely a legitimate topic here in Wellington.

The terms used by Kate Fox which describe and prescribe such behaviour are: reserve, the carefully restricted way of letting out emotions; and understatement, not being earnest about oneself, displaying well-pitched modesty.

The reasons for our prolific understating are not hard to discover: our strict prohibitions on earnestness, gushing, emoting and boasting require almost constant use of understatement. Rather than risk exhibiting any hint of forbidden solemnity, unseemly emotion or excessive zeal, we go to the opposite extreme and feign dry, deadpan indifference. The understatement rule means that a debilitating and painful chronic illness must be described as a "bit of a nuisance"; a truly horrific experience is "well not exactly what I would have chosen'; . . . an act of abominable cruelty is "not very friendly" . . . the Antarctic is "rather cold" and the Sahara "a bit too hot for my taste" . . . "I don't get it," said one exasperated informant [a foreign visitor] ... "How the hell are you supposed to know when 'not bad' means absolutely brilliant or when it just means 'OK'? Is there some secret sign or something that they use? Why can't they just say what they mean?"18 
For foreigners, it is very hard to learn this game and neither New Zealanders nor the English seem to make many allowances for misunderstandings here. So you either learn it, often after numerous setbacks, or go the hard way and resist such rules, staying true to your immigrant self, and getting sidelined. Even when $I$ get it about right, I am still totally confused. Not long ago, I was quite annoyed about some workplace procedure and wrote to my head of school, obeying the rules of 'moaning grammar' by sending a carefully worded email stating that I was 'slightly surprised' about this or that not happening. When we talked later, I mentioned that I had actually been quite furious about the aforementioned situation. She looked at me, totally astonished, and said, 'Yes, that was perfectly clear from your email.' I believe that only fellow immigrants can understand my surprise that my email had worked, that somebody would actually translate 'slightly surprised' into what I really felt and meant to say.

\section{Thoughts about modesty and the self-deprecation rule}

Self-deprecation naturally involves modesty, but it also requires saying the opposite of what we really mean, or at least the opposite of what we intend people to understand. It is often vital for maintaining good relationships and, funnily enough, a good level of understanding. The English have strict rules about modesty and, 1 believe, so do New Zealanders. There is the negative rule, like the prohibition on boasting and any form of self-importance, and the positive rule: actively prescribing self-deprecation and self-mockery. 'The modesty we display is generally false or, to put it more charitably, ironic. 19 The modesty rule seems to refer straight back to the New Zealand 'tall poppy' syndrome. Modesty rules are there to help everybody feel the same, to save face for the less gifted, to maintain an even social balance, and I believe they apply equally to both countries but belong or refer to a different social logic.

One of the characteristics of rules about conflict is that a straightforward complaint has to remain the last resort; complaints are dangerous because they potentially tip the balance in an already unstable relationship, are often read as an insult and are usually ineffective. Often complaints are suppressed and replaced by a good deal of cathartic moaning (not to be confused with whinging). Having a good moan is also a deeply embedded and elaborately English way of expressing oneself and relating to one another. Kate Fox cites phrases which directly relate to moaning, such as: 'typical', 'I knew that', 'mustn't grumble' and 'never mind'. The characteristic of a good English moan is its utter ineffectiveness. You moan to yourself or to the person next to you, even among a group of people, but never ever actually address the person or people who are being moaned about. 
That, to me at least, seems to be the same in New Zealand and is one of the daily miracles of living here. How could anything ever possibly improve if people are never told what is actually going wrong all the time? If you pluck up enough courage to disobey the moaning rule, things tend to get worse rather than better. I don't get it, unless there is some kind of social osmosis going on which I have yet to discover.

Fox distinguishes three modes of moaning or complaining, all equally ineffective and unsatisfying:

1. The silent complaint (rolling eyes, complaining among each other)

2. The apologetic complaint ('I am terribly sorry, but would you mind checking if it could be at all possible to get what I ordered about an hour ago?')

3. The loud, aggressive, obnoxious complaint (very rare in New Zealand, really only done by foreigners) which leads to no result at all.

Fox cites a frustrated American as saying 'that at some deep down fundamental level, the English just don't really expect things to work properly - do you know what I mean?' She agrees with this: because the English expect that everything might go wrong at any time, at least they are not taken unawares. ${ }^{20}$

I do not see this as the case in New Zealand; I get the feeling that people here genuinely hope that things will work out somehow, even if they hardly ever do. Well, at least they do in retrospect, eventually, even if they have to be re-defined to make them work out. Kiwi phrases for this include: 'good as gold', 'she'll be right', 'it'll be fine', 'box of birds', 'piece of piss', 'nothing to worry about, really' or just 'don't worry, that's fine' - which, of course, it hardly ever is. But what really matters is that we have all saved face by reassuring ourselves that it really does not matter, and also established that there is some degree of hope that things might work out in the future.

A wonderful example of how this interplay of moaning but also obeying rules of fairness (another intrinsically English/Kiwi trait) works in practice occurred when we attended our first New Zealand open-air concert as Bic Runga and her band played at Alana Estate in Martinborough. Not only did we ourselves make some typical immigrant mistakes and misjudgements, ${ }^{21}$ but the concert also offered me amazing insights into good and bad Kiwi behaviour, and also into great Kiwi humour, which can help solve problems in myriad ways.

The lawn area in front of the stage was reserved for people with blankets, sitting on the ground. Behind that, people were allowed to put up folding chairs, thereby being able to still see the stage without blocking anyone 
else's view. Slowly people arrived and settled on the ground, unfolding blankets and mats. There was, however, one couple in the front row who put up folding chairs and enjoying a long picnic. From time to time a band member would climb onto the stage, grab the microphone and announce that people on the ground on the lawn area were to sit down and those behind the little barrier were allowed to sit on chairs. Everybody looked at this couple; some people even started muttering a bit and point silently, but nothing happened. To my amazement, no usher person, no band member and certainly nobody from the crowd told the couple to move to the chair area. This would never have happened in Germany. Finally, Bic Runga came on stage and the concert started. The couple then simply folded their chairs away and sat down!

This concert was also clearly a 'great night out for the girls'. Women were in the majority and, although men seemed to enjoy the event too, most of them looked as if they were there treating their partner to something special. After a while, many women started dancing and singing and also tried to get their male companions to join in. A whole set of men in 'social dis-ease' could be observed. The women disrupted and challenged gender roles and showed a different expectation of what maleness could be; and men offered a wonderful array of Kiwiness: they watched the women dance, creating a secure distance from the groups of exuberant females, arming themselves with a drink in hand.

There are some well-established rules about maleness, especially Kiwi maleness. These make it very clear that the way to enjoy yourself in mixed company is to stay cool and slightly detached, ensure a steady drink supply and, most of all, be careful not to display too much emotion, especially in public, for fear of appearing unmanly or even homosexual. Again, the Bic Runga concert was a primarily female event to which many men seemed to have taken their partners to 'do the right thing', but also seemed utterly embarrassed when the women showed emotion by singing along, giving enthusiastic applause, dancing or, even worse, trying to get their male partners to dance. Gender relationships are too big a topic to be covered even superficially here, but it is a fascinating one when you like to study rules of behaviour. ${ }^{22}$

\section{A Friday night in town}

Finally I would like to address the topic of the New Zealand pub: a wonderful stage for enacting social drama, engaging in ritualistic conversation and figuring out social differences and pecking orders.

In stark contrast to many other countries, the English do not have table service at the pub. Kate Fox argues that this makes sense because of their social inhibitions: they need, according to Fox, all the help they can get to be 
able to strike up conversations with strangers, to relax and so on. Therefore, the counter and all that happens around it is vital to social behaviour in the English pub. She aptly describes the serving system as an invisible queue: everybody knows who will be served next. (In New Zealand this is not entirely true, as the staff are often too casual to follow this rule. Still, there is always hope.) Also, patrons usually know the 'first-served rule' and try to be helpful and let waiting staff know who is next. But that does not necessarily mean they will listen and act accordingly. ${ }^{2.3}$

So, in the social scene of the New Zealand pub there is plenty of opportunity for moaning, grumbling, turning around to your table and pulling faces and so on. Then, of course, when the barperson eventually serves you or, even better, may say, 'Sorry about the wait', you would not say, 'Well it's about time' or, 'This will require at least one free beer'; the Kiwi will just say, 'No worries, no problem, that's fine, can I have three beers, a coke and a sauv' blanc, thank you' (which basically translates to, 'Will you please allow me to spend $\$ 70$ on the next round?'), and return triumphant and much relieved to the table, hoping this is the only time they have to perform this service tonight.

This sometimes used to drive me mad, but I now find myself doing exactly the same thing. Although Kiwis don't actually verbalise the English saying (or rather social command) of 'don't make a fuss', this is still considered the proper behavioural norm; making a fuss is 'not on'. Also everybody here knows that complaining will just result in even less friendly behaviour from the opposed party, in this case the staff.

Kate Fox rightly claims that for many the pub is an essential part of everyday English life. You don't need to watch Coronation Street to realise this. There are also well known, but not necessarily well reflected on rules on pub behaviour, including how to order a beer or a round (no table service), how to tip the counter staff, how to 'queue' and how to conduct yourself in a conversation around your table. The not to be earnest rule applies, but also the balance between shouting and having arguments (which are allowed to be mildly controversial but never to be taken too seriously). The round in the pub is also mainly an affirmation of mateship and social bonding. Women are now often allowed into this but are also sometimes still more or less openly excluded. ${ }^{24}$ Some of these observations of the English will be familiar to the Kiwi pub goer, while others notably will not.

First of all, New Zealand settlement patterns often don't allow for daily pub gatherings after work, unless you work in the inner city. There is no such thing as the corner pub; when the suburbs started spreading out, the liquor licensing laws were tight and the population was never really dense enough to make corner pubs viable. So pub drinking seems more a weekly habit than a daily one. Friday nights are, for many New Zealanders, the 
night to go out and meet with friends, and some also go out on Thursdays. We have already hinted at the fact that New Zealanders do not really suffer from social dis-ease, they quite enjoy meeting people and even enjoy small talk and gossip, not just as a means to overcome social inhibition but as entertainment and social glue and a celebration of the end of the working week.

One of the really complicated matters on Friday nights is the system of round buying. Here a number of rules and guidelines come into play. Buying drinks for each other is connected to a strong notion of fairness and fair play and it also is a constant testing of these qualities around the members of drinking circles. Round-buying consists of a well-balanced display of reciprocity and generosity, a quiet caring for those who need to be looked after, the art of offering without being seen as either too pushy or, conversely, as trying to avoid buying your round.

There are invisible concentric circles of people who come into play when considering buying drinks. First, there are always people who belong to the regular inner circle; they are the ones who automatically buy and offer drinks to each other. Then there might be people occasionally joining or hanging around the table without necessarily sitting down; they may get offered the occasional drink by somebody who knows them better than the others or, even better, they might buy drinks for some people in the inner circle offering reciprocity of some kind (maybe for older obligations). Then there are people who might belong to other circles and, although one might get up and have a chat with them, buying each other drinks is out of the question; the relationship is too far off from the obligations of the inner circle, unless one drifts into their table round. An exception to these rules is visitors and guests from somewhere else, often overseas: they are taken straight into the round-buying system of the inner circle because the rules of general hospitality come into play.

Round-buying seems to me to be all about reaffirming social bonds, measuring and classifying mates from acquaintances, freeloaders from decent people. If some people don't pull their weight enough, the radars are on and typical New Zealand/English reactions will take place: eyebrow raising and moaning, and, eventually, some social sanctions might follow; not necessarily connected to the pub, but word will spread.

Women have an even more difficult role to play and there are rules and rules to this. First, they tend to drink less then men so they are not really expected to buy as many rounds. Then they might be seen as spouses, but that only stretches so far. There are also more subtle and complicated rules which I have to admit are still sometimes a mystery to me. But then I am a woman and an immigrant, so ... 


\section{There is still so much to do. Are the rules really so hidden?}

There are so many wonderful topics I cannot talk about here. I really would like to start to unravel the New Zealand system of social differences (but Anna Gruner will follow that up). I'd love to talk more about mateship, and also the quite different rules which apply to female friendships. I'd love to speak about the rules attached to dealing with housing and houses, to the interior of homes, the Kiwi summer season, the rules applying to celebrations, to shopping in the widest sense (something Peter Howland will do in his paper); there is the burning question of who is a New Zealander and who isn't (which is further examined by Amanda Gilbertson). This seminar series, and resulting articles, will hopefully provoke us to constantly observe and reflect upon 'New Zealandisms', even more than before. There is so much to do.

I This paper is an only slightly adjusted version of the opening seminar of the 'Watching the Kiwis' seminar series given in the Stout Research Centre for New Zealand Studies in March 2007. Although all other contributors turned their presentations into articles, 1 chose to leave mine as it was originally presented; this is partly to mirror the original spirit and content of the series and partly because this marked the beginning of a truly new research area for myself.

2 K. Fox, Watching the English: The hidden rules of English behaviour, London, 2004.

3 The original seminar series had some papers which unfortunately could not be included in this publication. These were Kon Kuiper on 'Mud. Blood and Mateship: Interpreting the Rituals of Rugby', Carolyn Morris on 'Farming the Pelennor Fields: Mythologised Landscapes and Farmer Subjectivity in the South lsland of New Zealand' and Katy Miller on 'Stir Fry: Fruit, Vegetables, Markets and Meanings in New Zealand'.

4 I like to thank my research assistant Jemima Sherpa for wonderful discussions of my paper and for editing the final version; James Urry and Amanda Gilbertson also offered valuable thoughts and feed back.

5 B. Anderson, Imagined Communities: Reflections on the origins and spread of nationalism, London \& New York, 1983; M. Herzfeld, Cultural Intimacy: Social poetics in the nationstate, 2nd ed., New York \& London, 2005; E.T. Hall and M.R. Hall, Understanding Cultural Differences, Yarmouth, 1990; B. Bönisch-Brednich, 'Multikulturelle Realität und wissenschaftliches Nationbuilding', unpublished conference paper, on 'Konzepte kultureller Differenz - interkulturelle Perspektiven' at the Institut für interkulturelle Kommunikation Ludwig Maximilan Universität, Munich, July 2008.

6 H. Bausinger, Typisch Deutsch. Wie Deutsch sind die Deutschen?, Munich, 2000; N. Barley, Native Land: The bizarre rituals and curious customs that make the English English, London, 1989; J. Paxman, The English: A portrait of a people, London, 1998; T. Tan, Culture Shock! Britain: A survival guide to customs and etiquette, $1^{\text {th }}$ ed., London, 1992: V. Ware, Who Cares About Britishness? A global view of the national identity debate, London, 2007; P.W. Preston, Relocating England, Manchester \& New York, 2004; S. Stern, These Strange German Ways, and the Whys of the Ways: A cultural guide to the Germans and their customs. Hamburg, 2000; S. Gikandi, Maps of Englishness: 
Writing identity in the culture of colonialism, London, 1996; G. Orwell, The English People, London, 1947.

7 Fox, p.14.

8 C.C. Catley and S. Nicholson, The Xenophobe's Guide to the Kiwis, London, 1996; A. Mitchell, The Half-Gallon Quarter-Acre Pavlova Paradise. Christchurch, 1972; A. Mitchell, Pavlova Paradise Revisited: The strange but endearing land where Kiwis live, Auckland, 2002; G. McLauchlan, The Passionless People, Auckland, 1976; J. Caldwell and C. Brown, 8 Tribes: the hidden classes of New Zealand, Wellington, 2007.

9 P. Howland, Lotto, Long-drops \& Lolly Scrambles: The Extra-Ordinary Anthropology of Middle New Zealand, Wellington, 2004.

10 Fox, p.2.

11 Fox, p.6.

12 Fox, p.22.

13 Fox, p.15.

14 Fox. p.16.

15 I have to thank James Belich for taking the time to discuss these issues with me (February/March 2007).

16 Fox, p.28.

17 Fox, p.26.

18 Fox, pp.66-67.

19 Fox, p.68.

20 Fox, pp. 197-200

21 How were we supposed to know that a statement on the ticket that the 'Doors open at $3 \mathrm{pm}$ ' actually meant the concert would start at $7 \mathrm{pm}$ ? That everybody would bring picnic baskets and feed family and friends; that one is expected to bring one's own blankets, cushions and folding chairs? We ended up having a lovely time, despite having nothing to eat and having to sit on the very dusty ground in our flash summer frocks. Next time, we'll know better.

22 For more on Kiwi masculinity, refer to J. Phillips, A Man's Contry? The Image of the Pakeha Male. Ist ed., Auckland, 1996; M. King, One of the Boys? Changing views on masculinity in New Zealand. Auckland, 1988.

23 Fox, pp.90-91.

24 Fox, pp.88-108. 